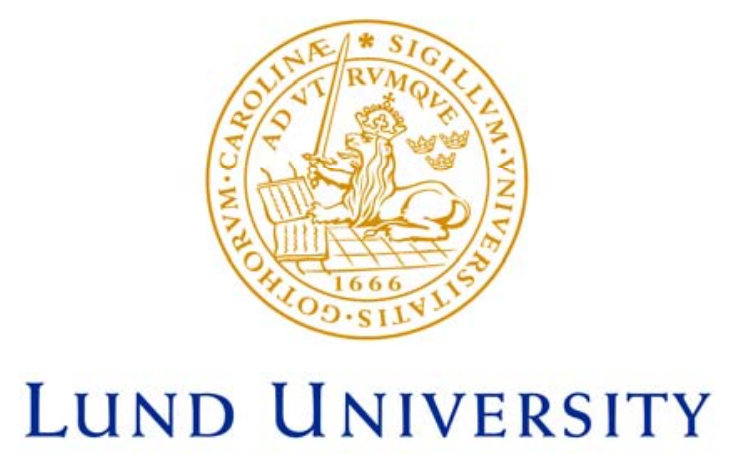

Faculty of Medicine

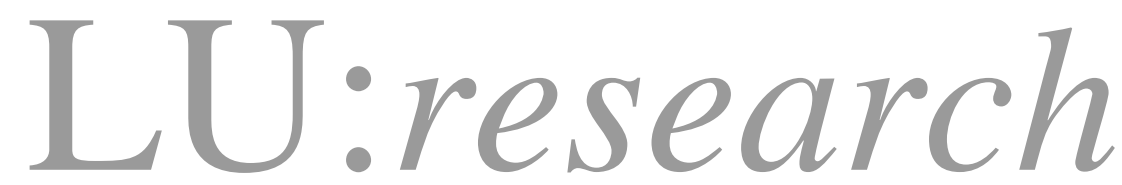

Institutional Repository of Lund University

This is an author produced version of a paper published in Annals of dyslexia. This paper has been peer-reviewed but does not include the final publisher proof-corrections or journal pagination.

Citation for the published paper: Johansson, Barbro B.

"Cultural and linguistic influence on brain organization for language and possible consequences for dyslexia: a review."

Ann Dyslexia, 2006, Vol: 56, Issue: 1, pp. 13-50.

http://dx.doi.org/10.1007/s11881-006-0002-6

Access to the published version may

require journal subscription.

Published with permission from: Springer 


\title{
Cultural and Linguistic Influence on Brain Organization for Language and Possible Consequences for Dyslexia: A Review
}

\author{
Barbro B. Johansson \\ Wallenberg Neuroscience Center \\ Lund University, Sweden
}

Current neuroimaging and neurophysiologic techniques have substantially increased our possibilities to study processes related to various language functions in the intact human brain. Learning to read and write influences the functional organization of the brain. What is universal and what is specific in the languages of the world are important issues. Most studies on healthy bilinguals indicate that essentially the same neural mechanisms are used for first and second languages, albeit with some linguistic and cultural influences related to speech and writing systems, particularly between alphabetical and nonalphabetical languages. Proficiency, age of acquisition, and amount of exposure can affect the cerebral representations of the languages. Accumulating data support the important role of working memory for acquiring high proficiency in the reading of native and second languages. It is proposed that longitudinal studies on second language acquisition are essential and that the specific problems related to second language learning in dyslexic children should have high priority.

Key Words: Alphabetic and nonalphabetic languages,

bilinguals, brain imaging, brain plasticity, culture, dyslexia, linguistics

Current neuroimaging and neurophysiologic techniques have sub-stantially increased our possibilities to study cognitive processes in the intact human brain. For the techniques used in the

Annals of Dyslexia, Vol. 56, No. 1, 2006

Copyright $@ 2006$ by The International Dyslexia Association ${ }^{\circledR}$

ISSN 0736-9387 
individual studies mentioned in this review, the readers are referred to the individual papers quoted. However, some short presentations and explanations to abbreviations used are given here. With positron emission tomography (PET) and functional magnetic resonance (fMRI), fluctuations in brain activity can be studied with a resolution from minutes (PET) to seconds (fMRI). Neuronal activity gives rise to very weak magnetic fields, which after shielding of the much stronger magnetic fields of the earth, can be registered at more than 300 points on the scalp simultaneously with a millisecond resolution with magnetoencephalography (MEG), an online technique showing where and when an activation starts and how it spreads to other regions. Similarly, small voltage fluctuations during neuronal activity — event related potentials (ERPs) — can be registered by multiple electrodes on the skull, a method that can be used even in infants. Voxel-based morphometry is a method that greatly has improved our abilities to study the anatomy of the living brain. Transcranial magnetic stimulation (TMS) is a neurophysiological technique that can temporarily excite or inhibit synaptic efficiency in specific areas and transiently alter brain function. For references to these methods, see Johansson (2006).

\section{LINGUISTIC INFLUENCE ON SPEECH RECOGNITION AND LANGUAGE CAPACITY IN INFANTS}

Sounds in the environment of a pregnant woman penetrate the tissue and fluid surrounding the head of the fetus and stimulate the inner ear during the last trimester of the pregnancy, and allow the fetus to react to vowels whereas consonants that are higher in frequency and less intense than vowels, are largely unavailable to them. Rhythmic patterns are probably detected (Abrams \& Gerhardt, 2000). Neonates show a right ear (i.e., left hemisphere) advantage for speech and a left ear (right hemisphere) advantage for music (Bertoncini et el., 1989; Best, Hoffman, \& Glanville, 1992; Pena et al., 2003), and they show a preference for the voice of their mother and for the music the mother was listening to during the late part of the pregnancy, indicating a capacity for implicit learning during fetal life.

Languages differ widely in stress and rhythm. Thus English is characterized by strong stress and irregular rhythm whereas Japanese has a regular rhythm and some changes in pitch but 
little stress. French newborns are able to discriminate between English and Japanese but fail to discriminate between English and Dutch that both have stress. When the newborns heard different combinations of sentences from English, Dutch, Spanish, and Italian, they could discriminate only when English and Dutch sentences were contrasted with Spanish and Italian sentences that have less stress and more regular rhythms, suggesting that newborns use prosodic, and more specifically, rhythmic information to classify utterances into broad language classes defined according to global rhythmic properties (Nazzi, Bertoncini, \& Mehler, 1998). Infants as young as 2 months of age listen longer to speech sounds than to nonspeech analogues that retain many of the spectral and temporal properties of speech signal, including pitch contour information (Vouloumanus \& Werker, 2004). A clear development with respect to the processing of different stress patterns relevant for word recognition takes place between 4 and 5 months of age in German infants (Weber, Hahne, Friedrich, \& Friederici, 2004).

Language input to infants has culturally universal characteristics designed to promote language learning such as louder and more extreme vowels, and it is syntactically and semantically simpler than speech directed to adults (Kuhl, 2004). By 6 months of age, speech perception abilities are attuned to the vowels of the language to which the infants are exposed (Kuhl, 2004; Kuhl et al., 1997), and the infants' consonant perception is attuned to the native language by 10 to 12 months of age (Werker \& Lalonde, 1988). Statistical learning-the detection of consistent patterns of sound in a continuous stream of sounds in which words are seldom surrounded by pauses-has been proposed to play a powerful role in infant word segmentation (Saffran, 2001, 2003; Saffran, Aslin, \& Newport, 1996), as well as in the transition from syllables to syntax (Saffran \& Wilson, 2003). However, in a language with strong stress like English, the stress plays an important role. When statistical and stress cues do not agree, 7-month-old infants attended more to statistical cues whereas 9-month-olds used syllable stress as a cue to segmentation of words, ignoring the statistical cues. Thus infants at different ages may use different segmentation strategies as a function of their current linguistic experience (Thiessen \& Saffran, 2003).

It has been proposed that phonetic elements of speech could be considered as phonetically significant articulatory gestures that generates these sounds (Browman \& Goldstein, 1992; Liberman \& Mattingly, 1985; Liberman \& Whalen, 2000), an 
idea that is consistent with the hypothesis that gestures may have played a decisive role in the development of the human language (Corballis, 2002, 2003; Fadiga, Craighero, Buccino, \& Rizzolatti, 2002; Floel, Ellger, Breitenstein, \& Knecht, 2003; Meister et al., 2003; Rizzolatti \& Arbib, 1998). One region that has attracted particular interest is Broca's area, traditionally looked on as a language area, which now is proposed to consist of partly overlapping subsystems that support various functions including motor imaging, object manipulation, grasping and planning (Nishitani, Schürmann, Amunts, \& Hari, 2005; Rizzolatti \& Craighero, 2004), and also music (Koelsch et al., 2004; Maess, Koelsch, Gunter, \& Friederici, 2001). Profoundly deaf infants of deaf parents display a manual babbling in a manner analogous to the vocal babbling of hearing infants (Petitto \& Marentette, 1991), and in sign language gestures can adequately substitute for sounds. Two spontaneous and rapidly developing sign languages in deaf populations are of particular interest. Within a community of deaf Nicaraguans that lacked exposure to a developed sign language, children have created a new sign language during the past 25 years. Its successive development, transforming gestures into a linguistic system, suggests that children possess language-learning abilities that enable them to organize their language without environmental stimulation or explicit guidance (Senghas, Kita, \& Özyürek, 2004). It is now the primary language of approximately 800 people, ranging in age from 4 to 44 (Senghas, 2005). Another sign language has emerged among three generations of deaf people in a Bedouin community in the Negev desert, a community of 3,500 where approximately $80 \%$ of the members are congenitally deaf, a much higher incidence than observed elsewhere (Sandler, Meir, Padden, \& Aronoff, 2005).

\section{HEMISPHERIC ASYMETRY IN AUDITORY PROCESSING}

Cortical asymmetries may have developed as a general solution to the need to optimize processing of the acoustic environment in both temporal and frequency domains (Zatorre, Belin, \& Penhune, 2002). Whereas consonants in speech requires a very high temporal resolution, a melody with durations shorter than about $160 \mathrm{~ms}$ is difficult to identify.

There is evidence that left hemisphere is superior in temporal processing and that the right is superior for spectral 
processing, including pitch and prosody, with the left auditory areas preferentially extracting information from 20-50 ms windows and the right homologues preferentially from 150-250 ms windows (Poeppel, 2001, 2003; Zatorre \& Belin, 2001).

Cortical regions that are outside the traditional left perisylvian areas in language processing are attracting increasing attention (Price, 2000). Frontal, temporal, and parietal regions, together with subcortical structure, are differentially involved in specific aspects of linguistic processing from word level to sentences. A new functional neuroanatomical model for language was proposed by Hickok and Poeppel (2004), arguing that the old idea of language organization from the time of Broca and Wernicke is insufficient because it cannot account for a range of aphasic syndromes, and it is linguistically and anatomically underspecified. In their model, the cortical fields in the posterior-superior temporal lobe (primary auditory cortex) on both sides are the primary substrate for constructing sound-based representation of speech, and beyond the initial representation, the signal is elaborated asymmetrically in the time domain with left nonprimary auditory areas preferentially extracting information from short $20-50 \mathrm{~ms}$ and the right homologues preferentially from long 150-250 ms integration windows. In analogy with theories of vision, they proposed that at least two pathways participate in speech perception in a taskdependent manner: a dorsal pathway that links auditory representation to motor representation and superior/parietal areas that also is the functional basis for verbal working memory, and a ventral pathway for lexical semantic representation (Hickok, Buchsbaum, Humphries, \& Muftuler, 2003; Hickok \& Poeppel, 2004; Poeppel \& Hickok, 2004).

After the initial acoustic analysis, the system has to extract segmental information such as phonemes, syntactic and lexicalsemantic elements, and prosodic information (i.e. accentuation and intonation phrases) and pitch may be used for lexical identification in spoken word recognition (Friedrich, Kotz, Friederici, \& Alter, 2004). In the dynamic dual pathway proposed by Friederici and Alter (2004), syntactic and semantic information is primarily processed in the left hemispheric temporofrontal pathway including separate circuits for syntactic and semantic information, whereas sentence level prosody is processed in the right hemispheric temporofrontal pathway. According to their model, the segmental lexical and syntactic information is processed in the left hemisphere, even when lexical differences are coded by tones bearing lexical meaning and 
word level stress, and it is exclusively the sentence level suprasegmental information, namely accentuation and boundary markings expressed acoustically by typical pitch variation, that is processed by the right hemisphere (Meyer et al., 2002).

Language impairment is most frequently seen after lesions in the left hemisphere but does occasionally occur after lesions on the right side. Functional imaging studies have shown that there is a graded continuum from left hemispheric to right hemispheric language lateralization in the general population (Pujol, Deus, Losilla, \& Capdevila, 1999). The recovery of function in aphasic individuals with apparently similar lesions varies. To determine the functional relevance of language lateralization assessed by measuring hemispheric perfusion differences during a word generation task, language was temporarily suppressed using a repetitive transcranial magnetic stimulation technique, applied either to the left hemisphere above Wernicke's area or to its homologue on the right hemisphere. Language disruption correlated with both the degree and side of lateralization and subjects with more bilaterality (weak lateralization) were less affected by either left- or right-side suppression than were subjects with strong lateralization to one hemisphere (Knecht et al., 2002). It was proposed that more evenly distributed language processing between the hemispheres would allow for better compensation after a unilateral lesion.

The advantage of the left hemisphere for most language tasks is a well-established fact. However, comprehension of stories, conversations, and text in natural language is a complex cognitive task in which the right hemisphere might have an important role. Accumulated evidence from neuropsychology, neuroimaging, and neuroanatomy suggests at least three roughly separable but highly interactive components of semantic processing (activation, integration, and selection), each with bilateral components with the right hemisphere component performing coarser computations for the same general process (see Jung-Beeman, 2005).

\section{BRAIN PLASTICITY}

The concept of brain plasticity implies that the brain is adaptable, and that neuronal connections and circuits are modified over time by exposure to incoming stimuli, experience, learning, specific activities, and training (Buonomano \& Merzenich, 1998; Hickmott \& Merzenich, 2002; Johansson, 2004a, 2004b; 
Pascual-Leone, Amedi, Fregni, \& Merabet, 2005). We can talk about developmental plasticity, training or activity depending on plasticity, and lesion-induced plasticity.

\section{DEVELOPMENTAL PLASTICITY}

There is a considerable capacity for crossmodal plasticity in early childhood with redundant connections between auditory and visual areas that gradually decrease between 6 and 36 months of age (Bavelier \& Neville, 2002; Neville \& Bavelier, 2002). Auditory localization and speech processing activate the visual cortex in congenitally blind humans (Roder et al., 2002; Weeks et al., 2000). Congenitally blind people, who cannot get any spatial information from vision, can localize sounds in the peripheral space better than sighted subjects (Lessard, Pare, Lepore, \& Lassonde, 1998; Roder et al., 1999), and their pitch discrimination is highly superior (Gougoux et al., 2004). Transient suppression of the occipital cortex reduces accuracy on a verb-generation task in congenitally or early blind individuals, demonstrating a causal link between occipital activation and language-related and verbal-memory tasks in these individuals (Amedi et al., 2004). Sign language activates different regions in hearing and deaf signers (Bavelier et al., 2001).

Whether a second language can completely replace the first language if a child loses all contact with the native language was studied in adult subjects born in Korea and adopted by French families at the age of 3 to 8 years (Pallier et al., 2003). They were fluent in their second language and had no conscious recollection of their native language, and they could not distinguish sentences in their native language from sentences coming from various unknown languages. Nor did they perform better in behavioral tests assessing a possible implicit memory for Korean than a control group of native French subjects who had never been exposed to the Korean language. The adopted subjects did not show any specific activation to Korean stimuli while they and native French adults listened to sentences spoken in Korean, and the groups did not differ when listening to other foreign languages unknown to the subjects, or to French. The cortical areas activated more by French stimuli than by foreign stimuli were similar in the adopted subjects and in the French native subjects. The only difference between the groups was a slightly larger area of activation to French in the Korean adopted individuals.

An earlier study on Hindu English speaking children in England that had only been exposed to Hindu during the first 
two years of their life had suggested that early experience may have a lasting effect. Although they were unable to discriminate the Hindi sounds $d$ and $t$, which are produced with more retroflexion than corresponding consonants in English, they needed only a small amount of familiarization and training for discrimination to return to native-like levels (Tees \& Werker, 1984). In a recent review, the authors offer the possible explanation that the individuals in their early study could have had continued exposure of Hindi-accented English, which might have reinforced the early experience of these sound (Werker \& Tees, 2005). In support for this view, they mention a study on adult Korean-born persons placed in English-speaking families in California as children, who were divided into groups based on the reexposure to Korean they had following adoption. Those with exposure as little as a few hours per month after the age of 6 years were able to maintain the same phonetic sensitivities as the native Korean speakers, whereas those without that exposure were no better than were other English-only speakers (Oh, Knightly, \& Au, 2003).

A recent MEG study comparing cortical organization of receptive language function in 92 monolingual native speakers of Mandarin (Putonghua) Chinese, English or Spanish showed a highly significant difference between Chinese and the two other groups. Whereas Spanish and English speakers showed a strong lateralization of activity sources to the left hemisphere, the degree of hemispheric asymmetry was significantly reduced in the Chinese group, which also showed greater individual variability in degree and direction of hemisphere symmetry so that a bilaterally symmetric profile emerged in the group data (Valaki et al., 2004). The group difference was first noted after the initial sensory processing of the word stimuli (>200 ms) and were primarily due to the degree of activation in the right temporoparietal region in the Chinese group, suggesting increased participation of this region in the spoken word recognition in Mandarin Chinese. Since tones convey much lexically meaningful information in Chinese, it was speculated that the prolonged participation of the right temporoparietal region in the Chinese group reflects the activation of neurophysiological processes that serve the analysis of lexical tones. Anatomical differences in the frontal, temporal, and parietal lobes between Englishspeaking Caucasians and Chinese-speaking Asians have been interpreted as evidence of neural plasticity shaped by the process of language acquisition during childhood (Kochunov et al., 2003). 


\section{PLASTICITY INDUCED BY SPECIFIC TRAINING AND ACTIVITIES}

While children learn to speak with no effort while being exposed to language, learning to read requires efforts and concentrated activities, and results in training-induced plasticity. Reading involves visual processing of written text, and the ease of reading acquisition is related to the development of phonological awareness. There is substantial evidence that the phonological loop, a component of working memory, plays an important role in reading (Baddeley, 2003; Baddeley, Gathercole, \& Papagno, 1998). Learning to read and write during childhood influences the functional organization of the adult brain (Castro-Caldas et al., 1998), and there is evidence that phonological processing and phonological awareness differ between literate and illiterate subjects (Petersson et al., 2000). The region of the corpus callosum, where parietal fibers cross the midline is thinner in illiterate than in literate women (Castro-Caldas et al., 1999).

In a test that isolated reading-related brain activity and minimized confounding performance effects in subjects from 6 to 22 years of age, reading was associated with increased activity in the left hemisphere middle temporal and inferior frontal gyri, and decreased activity in right inferotemporal cortical areas (Turkeltaub et al., 2003). In the youngest readers, activity in the left posterior superior temporal sulcus was associated with the maturation of their phonological processing abilities, results that extend previous evidence that posterior language areas mature earlier than anterior ones (Balsamo et al., 2002; Simos et al., 2001). The developmental decrease in the right ventral stream activity indicates a decreasing reliance on nonlexical form recognition systems for word identification, and provides strong support for Orton's theory (1937) that learning to read requires children to disengage posterior right hemisphere visual representations that interfere with proper word identification.

\section{LESION-INDUCED PLASTICITY}

In children with early brain lesions, the intact hemisphere can take over functions that normally are preferentially processed in the lesioned hemisphere. An example is a girl that underwent a left occipitotemporal resection of a benign tumor at the age of 4 years, thus after the development of speech but before the acquisition of reading, in which the visual component of reading was shifted to the right hemisphere whereas the verbal components remained strongly left lateralized (Cohen et al., 2004). Brain lesions also lead to changes and reorganization in the 
adult brain depending on location of the lesion and postlesion time (Frost et al., 2003; Johansson, 2000, 2004b; Seitz, Butefisch, Kleiser, \& Homberg, 2004; Ward, Brown, Thompson, \& Frackowiak, 2003). Issues relevant for this review will be discussed in connection with the bilingual brain.

\section{HEMISPHERIC SUBSPECIALIZATION IN LANGUAGE}

The result of a metaanalysis of studies on word reading within and across writing systems and languages indicates that writing systems utilize a common network of regions in word processing, but that localization within those regions suggests differences across writing systems (Bolger, Perfetti, \& Schneider, 2005). The analysis was based on 25 neuroimaging studies on English and other western European alphabetical languages, nine studies on native Chinese reading, five studies of Japanese Kana reading, and four studies of Kanji (morphosyllabic) reading.

\section{THE CASE OF CHINESE}

Studies on nonalphabetical languages are essential to understand the universalities and particularity of the organization of language systems. The unique properties of the Chinese writing system - its phonology, morphology, and semantics-have been presented in a special publication on cognitive neuroscience studies of the Chinese language (Kao, Leong, \& Gao, 2002). The difficulty in characterizing the Chinese writing system, whether to call it logographic, morphemic, or even morphosyllabic, is discussed by Perfetti, Liu, and Tan (2002) who conclude that the direct expression of morphemes in the writing system, as units of meaning and form, give the Chinese characters a status that is unique among the writing systems. For the complexity of how the Chinese characters (kanji) are used in the Japanese language, see Wydell (1998). Anatomical differences in the frontal, temporal, and parietal lobes between English-speaking Caucasians and Chinese-speaking Asians have been interpreted as evidence of neural plasticity shaped by the process of language acquisition during childhood (Kochunov et al., 2003).

In an fMRI study on brain activation and processing during reading of Chinese single characters with precise meanings, single characters with vague meanings, and two-character words, reading was characterized by extensive activity of neural systems with strong left lateralization of brain frontal and temporal 
cortices and right lateralization of visual systems, parietal lobe, and cerebellum (Tan et al., 2000). The location of peak activation in the frontal regions coincided nearly completely both for vague- and precise-meaning characters, as well as for twocharacter words, without dissociation in laterality patterns; and the left frontal activations were modulated by the ease of semantic retrieval (Tan et al., 2000). In tasks aimed to study brain activation during semantic and homophone decision separately, the peak activations resulting from semantic as well as homophone decisions were localized in the left middle frontal gyrus. More right hemisphere cortical regions were included in reading Chinese relative to reading English, suggesting that the left middle frontal area coordinated and integrated the intensive visuospatial analysis demanded by the configuration of the logographs and the semantic (or phonological) analysis required by the task (Tan et al., 2001).

The structure of nouns and verbs in Chinese is unique, and when Chinese subjects viewed a list of disyllabic nouns, verbs, and class-ambiguous words and performed a lexical decision on the target, both Chinese nouns and verbs activated a wide range of overlapping brain areas in distributed networks in the left and the right hemispheres, providing support for the prediction that linguistic typology and language-specific characteristics influence the neural representation of grammatical categories, and that the language-specific properties of the Chinese grammar affect the representation, processing, and acquisition of reading ( $\mathrm{Li}$, Jin, \& Tan, 2004). To what extent differences in processing of verbs and nouns exist in alphabetical languages is controversial. Data from a recent study (Shapiro et al., 2005) are in agreement with the notion that verbs and nouns are essentially processed by a common cortical network, mainly within the left hemisphere, and the authors discuss possible methodological explanations to the different results obtained.

It has been argued that phonological processing may be bypassed in silent reading in Chinese. However, Ziegler, Tan, Perry, and Montant (2000) have shown that Chinese characters with a high phonological frequency are processed faster than characters with a low phonological frequency, despite the fact that they were matched on orthographic frequency, thus suggesting that part of the word frequency effect may be phonological. These data support the notion of a universal phonological principle (Perfetti, 2003) according to which phonologic information is activated early and at lexicality as a constituent of word identification. 
Pinyin is an alphabetical phonetic system used to assist children in learning to read Chinese characters (Leong, 1997, 2002). A certain level of phonological transfer was observed in 46 Chinese-English bilingual 8-year-old children who attended Grade 2 and 3 in English classes in public schools, and Grade 2 and 3 Chinese in weekend Chinese school where they were taught Chinese characters and Pinyin simultaneously (Wang, Perfetti, \& Liu, 2005). All children learned Chinese as their first language but most of them at the time of the study spoke both languages at home. The Pinyin naming and English reading skills facilitated each other, and Chinese tone processing skill contributed significantly in predicting English pseudoword reading, even when English phonemic-level processing skill was taken into consideration. It was argued by these researchers that the relevant skill involved in Chinese tone processing is encoding phonological information. As expected, orthographic skills in Chinese did not predict reading skills in English.

Comparing syllable and single phoneme onset awareness in kindergarten and first grade children in Toronto, Hong Kong, and Xian, McBride-Chang, Bialystok, Chong, and Li (2004) showed that the development of phonological awareness in different orthographies is influenced by both language and writing systems with instruction also playing a role. Syllable awareness was found to be a relatively strong predictor of Chinese character reading both in Xian and Hong Kong, but phoneme onset awareness, a strong predictor of English reading, was not. Differences between children in Hong Kong and Xian suggested that Pinyin, used in Xian only, may promote phonological awareness, even at the syllable level. In another recent study, it is shown that the ability to read Chinese is strongly related to the writing skills of the child, and that the relationship between phonological awareness and Chinese reading is much weaker than in alphabetical languages (Tan et al., 2005). These authors propose that the role of logograph writing in reading development is mediated by two possibly interacting mechanisms. One is orthographic awareness, which facilitates the development of effective links among visual symbols, phonology, and semantics; the other mechanism involves the establishment of motor programs that lead to the formation of longterm motor memories of Chinese characters.

\section{THE CASE OF JAPANESE AND KOREAN}

There is evidence that the occipitotemporal region comprises subregions, with each sensitive to a distinct processing level of 
visual words (Cohen et al., 2002). The neural code for written words must be abstract because we can recognize words regardless of their location, font, and size; yet it must be sensitive to letter identity and letter order (Dehaene, Cohen, Sigman, \& Vinckier, 2005). In a comparison between the two Japanese scripts kanji (logographic Chinese characters) and kana (phonetic script representing syllables or morae), a shared visual occipitotemporal activation was observed for words in the two scripts with slightly more mesial and right predominant activation for kanji and with greater occipital activation for kana script. Word repetition produced significant priming, regardless of whether the words were presented in the same or different script, suggesting that cross-script convergence occurred at a semantic level (Nakamura et al., 2005). In another study comparing the two scripts in terms of hemispheric asymmetry for initial encoding and lexical representation, a right visual field (left hemisphere) advantage for the processing of kana was observed, but no lateralized advantage for kanji stimuli was found. Words written in kana elicited a priming effect when projected to either visual field. Kanji characters elicited a late-developing and eventually stronger priming effect of words projected to the left visual field, suggesting greater involvement of the right hemisphere. However, the results from kanji stimuli were more complex with greater interactions than the results from kana stimuli (Hanavan \& Coney, 2005).

The Korean language can be written both in Hangul, an alphabetical script with 24 symbols, each representing a phoneme, and Hanja, which consists of characters originally borrowed from the Chinese. In a study, Cho and Chen (2005) showed that when the task was either naming or semantic categorization, Korean readers had to respond to words either in a pure context with words from one single script or in a mixed context with words from the two scripts. For Hangul words, a significant word frequency effect was seen in categorization but not in naming, and a reliable script-switching effect was seen in naming but not in categorization. In contrast, regardless of the task, a strong word frequency effect was obtained for Hanja words, but a significant script-switching effect was only observed in categorization, thus suggesting that the strategies adopted in processing the two scripts are determined both by task demand and nature of the script (Cho \& Chen, 2005). 


\section{STRUCTURAL AND FUNCTIONAL PLASTICITY IN THE BILINGUAL BRAIN}

\section{STRUCTURAL PLASTICITY}

Neuroimaging of the brains in bilingual and multilingual subjects make it possible to study the interactions between a prewired neurobiological substrate and environmental influences. Learning a second language increases the density of grey matter in the left inferior parietal cortex, and the degree of structural reorganization is modulated by the proficiency attained and the age of acquisition (Mechelli et al., 2004). In the first part of their study, all volunteers were native English speakers of comparable age and level of education: 25 monolinguals who had little or no exposure to a second language; 25 early bilinguals who has learned a second European language before the age of 5 years and who had practiced it regularly since; and 33 late bilinguals who had learned a second European language between the age of 10 and 15 years and practiced it regularly for at least five years. The grey matter density was greater in both early and late bilinguals in the left inferior parietal cortex, with a similar trend in the right hemisphere and with a greater effect in the early than in the late bilinguals in both hemispheres. In the second part of the study, 22 native Italian speakers who had learned English as a second language at the age of between 2 and 34 years, the second-language reading, writing, speech comprehension, and production were assessed in a battery of neuropsychological test. The overall proficiency correlated negatively with age at acquisition and with the grey matter density in exactly the same left inferior parietal region that had been identified in the first part of the study.

\section{FUNCTIONAL PLASTICITY}

Kim, Relkin, Lee, and Hirsch (1997) carried out an early fMRI study on bilinguals exposed to two languages in infancy and six late bilinguals in early adulthood, in all covering 10 languages both alphabetical and nonalphabetical. The results showed that activation sites for the two languages tend to be spatially distinct in the Broca's area when the second language was learned late in life and not when acquired in early childhood, whereas Wernicke's area showed little or no separation of activity regardless of age of acquisition.

Bilinguals Speaking Different Alphabetical Languages (English, Spanish, Catalan, Italian, and German). Perani et al. 
(1998) studied the effect of early and late acquisition of second language in highly proficient bilinguals with a group of ItalianEnglish bilinguals that acquired the second language after the age of 10 years, and a group of Spanish-Catalan bilinguals that acquired the second language before the age of 4 years. The results suggested that at least for pairs of languages that are fairly close, attaining proficiency is more important than age of acquisition as a determinant of the cortical representation of the second language. In a later study comparing Spanish-born and Catalan-born bilinguals who had acquired either Spanish or Catalan as a first language, and who were exposed to the second language at 3 years of age and had been using both languages in daily life with a comparable level of proficiency, Perani et al. (2003) found less extensive brain activation was associated with lexical retrieval in the first language acquired. However, the usage/exposure to the second language (Spanish) was less intensive in the case of Catalan-born bilinguals, and when speaking Spanish, a more extensive activation indicated that both age of acquisition and language exposure affect the pattern of brain activation in bilinguals, even if both languages are acquired early and with a comparable level of proficiency. Illes et al. (1999) carried out a study to examine whether semantic processes in English and Spanish are mediated by a common neural system in fluent bilinguals who acquired their second language (either English or Spanish) at the age of about 10 years, thus several years after acquiring their first language. The results demonstrated a shared frontal lobe system for semantic analysis, indicating that the two languages do not require the addition of new cortical regions for semantic processing in the second language.

In Italian-German bilinguals who learned the second language at different ages and had different proficiency levels, the pattern of activity for semantic judgment was largely dependent on proficiency level (Wartenburger et al., 2003). The age of acquisition mainly affected the cortical representation of grammatical processes, supporting the view that both age and learning and efficiency affect the neural substrates of second language processing with a differential effect on grammar and semantics. In a study of the effects of 18 variables on Dutch and English lexical decision, word naming in Dutch-English bilinguals indicated the effects of language (orthographic depth), task requirements, and the participants' language proficiency in Dutch and English (De Groot, Borgwaldt, Bos, \& van den Eijnden, 2002). 
Early and Late Bilinguals: Native Language Shaping Neural Systems. Proficient Mandarin-speaking Chinese and English bilinguals exposed to both languages early in life utilized common neuroanatomical regions during the conceptual and syntactic processing of visually presented sentences irrespective of the differences in surface features (Chee et al., 1999). Differences in magnitude of activity but not in peak activation at the single word level were observed in Mandarin-English bilinguals exposed to the second language before 6 years of age (Chee, Tan, \& Thiel, 1999). There is, however, later evidence that the native language shapes the neural systems activated in a second language in bilingual individuals. Tan et al. (2003) showed that the phonological processing of Chinese characters in adult bilingual Chinese-English speakers recruited a neural system involving left middle frontal and posterior parietal gyri. These are cortical regions that are known to contribute to spatial information representation, spatial working memory, and coordination of cognitive resources as a central executive system assumed to be relevant to the unique features of Chinese logographic characters that map onto monosyllabic units of speech. When bilingual subjects performed a phonological task on English words, the same neural system was most active, whereas brain areas mediating English monolinguals' fine-grained phonemic analysis were only weakly activated. Tan et al. (2003) suggested that their Chinese-English bilingual subjects were applying the system of their native language (Chinese) to reading in English, and that the lack of letter-to-sound conversion rules in Chinese led these Chinese readers to be less capable of processing English by the analytic reading system on which English monolinguals rely. These findings lend support to the notion that early language experience tunes the cortex and that second language reading is shaped by first language for bilinguals.

Chee, Soon, Lee, and Pallier (2004) presented evidence to suggest the importance of phonological working memory in language acquisition. These researchers studied the neural correlates of phonological working memory in "equal bilinguals" with high proficiency in both English and Chinese, and "unequal bilinguals" proficient in English but not in Chinese, with both groups matched on measures of general intelligence and working memory. The 15 equal bilinguals and the 15 unequal bilinguals all had English as the first language, were exposed to both languages before 5 years of age, and had at least 10 years of formal training and under social pressure to be bilingual. Although unequal bilinguals did not differ from the equal bilin- 
guals in simple working memory tasks, the load-dependent increase in cortical activation was more focused in the equal bilinguals, thus suggesting that more optimal engagement of phonological working memory may be correlated with better second-language attainment (Chee et al., 2004).

Using functional MRI to study verbal working memory in nonfluent Chinese-English bilinguals, Xue, Dong, Jin, and Chen (2004) found the volume of activation was greater for the second language, English, than for Chinese. These results suggested that working memory in the two languages was mediated by a unitary neural system in the frontoparietal region capable of recruiting surrounding cortical resources to meet the increased computational demand caused by low second language proficiency. However, the authors were cautious in their interpretation of overlapping brain activation when processing first and second languages.

The results of the various imaging studies are in agreement with earlier behavioral studies on children, demonstrating that the nonword repetition span, a test used for evaluation of the phonological loop, is a good prediction for the ability to learn a foreign language (Baddeley et al., 1998; Cheung, 1996; Service, 1992).

Audiovisual Integration in Language Processing in Bilinguals. Perception of our environment is based on integration of input from various sensory modalities (Calvert, Campbell, \& Brammer, 2000; Wallace, Ramachandran, \& Stein, 2004). A classical example of auditory-visual integration is the so-called McGurk effect, demonstrating that the sound $p$ dubbed onto a facial display articulating $k$ elicits the fused percept $t$ (McGurk \& MacDonald, 1976). If the visual and auditory inputs agree, a facilitating effect can be obtained, and recent data indicate that visual speech speeds up the neural processing of auditory speech (van Wassenhove, Grant, \& Poeppel, 2005). In the perception of a second language, listeners often fail to hear the difference between certain nonnative phonemic contrasts. Spanish-dominant Spanich-Catalan bilinguals have difficulties with the Catalan e and $\varepsilon$ when presented only auditorily or only visually. However, when the same speech events were presented audiovisually, they are sensitive to the phonemic contrast, suggesting that visual speech gestures enhance second language perception at the level of phonological processing by way of multisensory integration (Navarra \& Soto-Faraco, 2005).

Bilinguals with Language Reorganization due to Brain Pathology. A striking feature seen in bilinguals with aphasia is different impairment for apparently similar lesions (Paradis, 
1995). Selective impairment of reading and writing in only one language may also occur, and the impairment can be transient or permanent. Sites where electrical stimulation interferes with naming in the lateral cortex of the dominant hemisphere in bilingual or multilingual individuals have indicated that different languages can be selectively disrupted (Lucas, McKhann, \& Ojemann, 2004; Ojemann \& Whitaker, 1978). It is a procedure that is done in patients with severe therapy-resistant epilepsy or brain tumors in order to avoid damaging language areas when part of the brain tissue has to be removed. A study on 25 bilingual patients representing seven first languages and nine second languages, and 117 monolingual patients, supported the existence of both language-specific and shared modules. Second language specific sites were located exclusively in the posterior temporal and parietal lobes. A comparison between the bilingual and monolingual patients demonstrated that the acquisition of a second language did not grossly alter the cerebral representation of the primary language areas but indicated that the second language may be restricted from certain perisylvian language areas dedicated to the first language (Lucas et al., 2004).

In another intraoperative stimulation study, the specific aim was to determine reading sites in 35 monolingual and 19 bilingual or multilingual patients with brain tumors with French as their native language and a mixture of second languages, with 44 tumors in the left and 10 in the right hemisphere. Roux et al. (2004) observed considerable individual variability and noted partial overlap between reading and naming sites. Reading extended over a larger zone than those found during naming and was occasionally also found in the nondominant hemisphere. Interferences with reading were generally found in many small cortical areas with intervening areas evoking no interferences (Roux et al., 2004).

With intracortical recordings, a large number of very small areas can be studied in the area explored, giving a much higher resolution than can be achieved in imaging of the brain in healthy individuals. One problem with the interpretation of such studies is that both epileptic activity and tumors can alter the cortical representation maps. In a MEG study on 21 patients with left temporal lobe epilepsy and 23 patients with left hemispheric tumors (mean age 54 years, range 13-76) Pataraia et al. (2004) noted an atypical language lateralization in $43 \%$ of the patients with epilepsy and $13 \%$ of the tumors. The results showed the majority of patients with seizure onset before age 5 
had atypical language lateralization, and the precise location of receptive language-specific cortex within the dominant hemisphere was atypical in 30\% of the patients with tumor and $14 \%$ of those with epilepsy. Further, early onset of epileptic seizures was found to be strongly associated with atypical language lateralization whereas tumors in the dominant hemisphere resulted in an intrahemispheric reorganization of linguistic functions (Pataraia et al., 2004). These results are in agreement with other studies on brain tumors (Kunesch et al., 2003; Seitz et al., 1995). The differences between the two groups are most likely due to an earlier at onset of epileptic foci than of brain tumors. Considerable variability was found in the localization of language sites in 4- to 16-year-old children with a relative paucity of language sites in all perisylvian cortices in the younger age group (Ojemann, Berger, Lettich, \& Ojemann, 2003).

Problems with using Brain Lesions for Localization of Brain Function. There is often a discrepancy between the imaging of language localization in healthy individuals and in patients with brain lesions. The differences between in vivo imaging of healthy individuals and studies on patients with brain lesions can have several explanations. Lesion studies assume that discrete anatomical modules deal with different cognitive functions, and inform the region required for a particular function but giving little information about networks. The direct preoperative electrical recording can sample neural activity at spatial scales ranging from single cells to distributed cell assemblies, which is important as a correlate to basic brain research (Engel, Moll, Fried, \& Ojemann, 2005). It was the first method used to study and localize cortical regions important for specific brain functions, and it has provided much d information. However, there are anatomical differences between individuals, and the plasticity in connection with lesions varies and the studies are usually restricted to small brain areas. The problem with using human brain lesions to infer function is discussed extensively by Rorden and Karnath (2004) who argue that it still is an important complement to the newer methods, but it also has limitations, as discussed in the concluding remarks of this paper.

\section{BRAIN ACTIVATION IN READING DISORDERS}

Epidemiological data indicate that reading ability and disability occur along a continuum, with reading disability representing 
the lower tail of a normal distribution of reading ability (see Shaywitz \& Shaywitz, 2005). Focal abnormalities have been observed bilaterally in the planum temporale, inferior temporal cortex, and cerebellar nuclei in a recent in vivo anatomic study of gray matter volume in dyslexic subjects, from four different families and characterized by a proband with persistent severe developmental dyslexia and at least one first-degree relative with either clinically evident or compensated dyslexia (Brambati et al., 2004). Reading difficulties have also been associated with structural abnormality in the white matter (Klingberg et al., 2000).

\section{READING DISORDERS IN ALPHABETIC LANGUAGES}

It was proposed early that the cognitive processes engaged when reading a word overlap with those engaged when naming a known object (Geschwind, 1965), and naming performance in kindergarten represents a predictor of later reading ability (Wolf \& Goodglass, 1986). Dyslexic subjects, impaired on reading, spelling, and naming speed, were matched for age and general ability with control subjects and scanned using reading words and naming of objects. Relative to the control group, the dyslexic participants showed reduced activation in the left occipitotemporal area during both word reading and picture naming, even in the context of intact behavioral performance during scanning. The level of activation thus indicated a common neurological basis for deficits in word reading and picture naming in developmental dyslexia. It was suggested that this area might act as an interface in the retrieval of phonology from visual input (McCrory, Mechelli, Frith, \& Price, 2005). However, damage to this region affects reading more than picture naming. It has been proposed that selective impairments of reading might be due to the fact that the right occipitotemporal region can sustain object naming better than it does reading (Price \& Mechelli, 2005). Angular gyrus, a temporoparietal region that connects with visual association areas and posterior language areas is activated in English speaking adults during single word reading but not in adults with persistent dyslexia (Horwitz, Rumsey, \& Donohue, 1998), and in dyslexia, the blood flow reduction predicted severity of the reading problem (Rumsey et al., 1999).

In a PET scan study, Paulesu et al. (1996) found their five compensated adult developmental dyslexics to be significantly impaired in phonological processing, manifested in such tasks as rhyming, short-term memory, and Spoonerism. Broca's area 
was activated during the rhyming task and temporoparietal cortex during the short-term memory task. In contrast to normal controls, these areas were not activated in concert, leading to the proposal that the defective phonological system of the dyslexics was due to a weak connectivity between anterior and posterior language areas (Paulesu et al., 1996). One other study of compensated adult dyslexics likewise found that in spite of compensation for the reading problems, the brain activation differs from controls (Ingvar et al., 2002).

Comparing English, French, and Italian subjects with dyslexia and their controls, Paulesu et al. (2001) found that their Italian dyslexics performed better on reading than did their English and French dyslexics, but all dyslexics were equally impaired relative to their controls on reading and phonological tasks. PET scans during explicit and implicit reading showed the same reduced activity in a region of the left hemisphere in dyslexics from all three language groups in the three countries, with the maximum peak in the middle temporal gyrus and additional peaks in the inferior, superior temporal, and middle occipital gyri. The difference in performance was attributed to the shallow orthography of the Italian language. Paulesu et al. (2001) concluded that there is a universal neurobiological basis for dyslexia, and that differences in reading performance among dyslexics of different countries are due to different orthographies and cultural diversity.

The same English, French, and Italian dyslexic subjects who took part in the Paulesu et al. (2001) PET study later participated in a voxel-based morphometry study by Silani et al. (2005) to assess consistency in functional imaging and brain morphometry. The results demonstrated that the earlier described regions with altered activation correlated with altered density of gray and white matter of specific regions with no difference between the three languages studied. The grey matter density was reduced in the left middle temporal gyrus and increased in the part posterior to the reduced grey matter region. The higher the density in this region, the more impaired were the subjects in the reading tasks as determined in the earlier study by Paulesu et al. (2001). Silani et al. (2005) speculated that the increased density posterior to the apparent atrophy was due to ectopias in the white matter that could not be separated from gray matter by the method used. Considering the fact that the prevalence of ectopias in dyslexia is still uncertain, that the linear regression analysis was performed with behavioral reading data from the study published four years earlier, and that two 
other studies using voxel-based morphometry have given different results, more investigations are needed regarding the relation between morphology, imaging, neurophysiology, and behavior in dyslexic individuals, and their relation to the languages studied. As mentioned earlier, anatomical differences in the frontal, temporal, and parietal lobes between Englishspeaking Caucasians and Chinese-speaking Asians have been observed with the same anatomical technique (Kochunov et al., 2003).

In terms of amelioration and intervention, several studies indicate that it is possible to effect partial remediation of the language processing deficits with possible alterations to neural systems specialized for reading (Eden et al., 2004; B.A. Shaywitz et al., 2004; Temple et al., 2003). Shaywitz et al. (2004) carried out the largest imaging study of reading intervention for three experimental groups of 6- to 9-year-old American children: 37 in experimental evidence-based phonological intervention, 12 in community intervention, and 28 in community control. The results showed that the children in the experimental intervention group made significant gains in reading fluency and demonstrated increased activation in the left hemisphere region, including the inferior frontal gyrus and the middle temporal gyrus; and one year after the intervention had ended, the children were still activating bilateral inferior frontal gyri and left superior temporal and occipitotemporal regions. A partial remediation of language processing deficits in 8- to12-year-old dyslectic children studied before and after a training program correlated with the magnitude of increased activation in left temporoparietal cortex and left inferior frontal gyrus, as well as in frontal and temporal regions in the right hemisphere (Temple et al., 2003). Even in adult individuals with developmental dyslexia, a phonologically targeted training resulted in functional gains associated with activation of bilateral parietal and right perisylvian cortices (i.e., left hemisphere regions engaged by normal readers), and, in addition, compensatory activity in the right perisylvian cortex (Eden et al., 2004).

\section{DISORDERS IN JAPANESE AND CHINESE}

The prevalence of developmental dyslexia has been reported to be lower in Japan than in populations with alphabetical languages (Miyazaki et al., 1995). Although more studies are needed to verify those data, a possible explanation has been put forward for a possible lower incidence in Japan in a recent 
publication. Two different kinds of writing systems are used in Japan: kanji, ideograms originating from Chinese characters; and kana, phonograms that can be written in two ways (hiragana and katakana). But both are phonetic systems in which each consonant is followed by a vowel forming a syllable (e.g., ka, ki, ku, ke, and ko). Hiragana is the first kana writing system taught to most Japanese children. In young adult Japanese volunteers, Seki, Okada, Koeda, and Sadato (2004) found that phonological manipulation (vowel exchange) resulted in different brain activation, depending on whether the presentation of the stimuli was auditory or visual. Consistent with studies on alphabetical languages, the auditory task induced activation of the posterior parts of the superior temporal sulci, whereas the intraparietal sulci implicated for visuospatial tasks were active during the visual presentation of the phonological manipulation. The cerebellar vermis was activated by both tasks. Possibly, an impairment in phonological awareness in Japanese children may be more easily compensated for by the kana system, allowing an alternative visual strategy to conduct phonological awareness tasks (Seki et al., 2004). The finding of a report on an English-Japanese bilingual, who is dyslexic in English but not in Japanese (Wydell \& Kondo, 2003), is in agreement with that hypothesis that should be further tested.

In Chinese readers, dyslexia is associated with reduced activity in the left middle frontal gyrus (Siok, Perfetti, Jin, \& Tan, 2004), which carries out the representation and working memory of visuospatial and verbal information, and coordinates cognitive resources as a central executive system (Courtney et al., 1998). Two regions in the right hemisphere differed; normal readers showed stronger activation in right midinferior frontal gyrus whereas impaired readers showed stronger activation in right inferior occipital cortex. Right midinferior frontal regions contribute to fluent Chinese reading (Tan et al., 2001), and the increased activity of right inferior occipital gyrus thought to be engaged in visual processing of Chinese characters (Tan et al., 2000) suggests that impaired Chinese readers also struggle in the visuospatial analysis of printed characters. The data are consistent with the idea that cognitive strategies for reading development tune the cortex (Tan et al., 2003). A recent detailed study on the different reading problems in three dyslexic Chinese children indicates that the prevalence of subgroups of dyslexia in Chinese children needs to be further studied (Shu et al., 2005). 


\section{DYSLEXIA AND SECOND LANGUAGE LEARNING}

To determine whether failure to learn a second language is due to linguistic factors, specific learning problems such as dyslexia, or sociocultural factors is an important and often not easy task (Geva, 2000; Lundberg, 2002). Multilingual children, common among immigrants, may have to start learning to read in a new majority language. Tradition and cultural conditions in homes, communities, and school must be considered as well as motivation, personality factors, and poor self-esteem (Lundberg, 2002). Given sufficient exposure to the majority language, it is possible to assess a range of phonological skills among speakers of minority languages using the same battery of tasks as for native speakers (Miller-Guron \& Lundberg, 2003).

Chinese dyslexic children encountered difficulties in learning English as a second language, and they are generally weak in phonological processing both in Chinese and English (Ho \& Fong, 2005). Phonological skills were found to correlate significantly with English reading but not with Chinese reading in the dyslexic children, indicating that there are both common and specific causes to reading difficulties in the two languages. A group of dyslexic 12-year-old Norwegian children who had been taught English as a second language since the first grade were given a number of verbal and written tasks, and found to differ significantly from the control group in all tasks (Helland \& Kaasa, 2005). However, subgrouping the dyslexic children by comprehension skills revealed only minor differences to controls between the group with good comprehensive skills and major differences between the control group and the subgroup with poor comprehension skills.

There may be exceptions to the common experience that the second language reading is more difficult for a dyslexic child than reading in the native language. For some native Swedish dyslexics, it is easier to read and understand English than Swedish (Miller-Guron \& Lundberg, 2000). Swedish children are exposed to English long before school through television, films (subtitled rather than dubbed), and music. Less emphasis on reading, writing, and spelling in the English teaching, alternative reading strategies, positive early experience of the language, and social, emotional, and motivational factors might partly explain the apparently paradoxical observation.

Another example that does not support that reading problems in the native language necessarily leads to worse problems 
in a second language is a study on Arab-Canadian bilingual children by Abu-Rabia and Siegel (2002). These researchers tested word and pseudoword reading, language proficiency, and working memory in 56 bilingual Arab-Canadian children 9-14 years of age who had lived in Canada for more than two years. The majority of the children came from a low socioeconomic level. English was their main instructional language, but Arab was the language spoken at home, and they attended Arabic Heritage Language programs for three hours a week where they received instruction in reading, and writing Arabic. The majority of the children showed at least adequate proficiency in both languages. The children were arbitrarily divided into a larger group of good and a smaller group of poor readers based on their scores in Arabic word reading. For the children with normal reading skills, all the reading and language skills that were measured were equivalent to those of monolingual English-speaking children except for the English orthographic test. The bilingual Arabic-English children who had reading problems in English had the same problems in Arabic. However, their scores in the English pseudoword reading, word spelling, and some of the phonological test were higher than in a control group of monolingual English reading-disabled children, results that were proposed to be due to a positive transfer from the regular nature of Arabic orthography. As the monolingual English- speaking children came from a higher socioeconomic society than the bilingual children, socioeconomic factors are unlikely to have contributed to the result.

There is evidence for impaired multisensory interactions in dyslexia (Hairston et al. 2005; Laasonen et al., 2000; Lassonen, Lahti-Nuuttila, \& Virsu, 2001; Laasonen, Service, \& Virsu, 2002). It would be interesting to study whether concomitant audiovisual presentation that has been shown to benefit nondyslexic bilinguals (Navarra \& Soto-Faraco, 2005) would benefit bilingual dyslexics.

\section{DOES MUSIC OR MUSICAL TRAINING FACILITATE LANGUAGE AND READING?}

It has been proposed that musical training may have a transfer effect on other cognitive functions including language. In a study on early reading ability in 504 -year-old and 50 5-yearold Canadian children, music skills were found to correlate significantly with both phonological awareness and reading 
development. Regression analyses indicated that music perception skills contributed to predicting reading ability, even when variance due to phonological awareness and other cognitive abilities (mathematics, digit span, and vocabulary) had been accounted for, suggesting that both linguistic and nonlinguistic general auditory mechanisms may be involved in reading (Anvari, Trainor, Woodside, \& Levy, 2002). Formal music training has been shown to enhance verbal but not visual memory (Ho, Cheung, \& Chan, 2003; Kilgour, Jakobson, \& Cuddy, 2000). Music training facilities pitch processing in both music and language (Schon, Magne, \& Besson, 2004), and it is associated with enhanced ability to perceive prosody in speech (Thompson, Schellenberg, \& Hussain, 2003, 2004).

Using musical aptitude tests specifically designed for dyslexic children, Overy, Nicolson, Fawcett, and Clarke (2003) found that 7- to 11-year-old dyslexic children scored higher than controls on three tests of pitch skills, possibly attributable to slightly greater musical experience, but lower than the control group in seven out of nine tests of timing skills. The dyslexic children had particular problems with rapid temporal processing, and the skill of tapping out the rhythm of a song correlated with spelling ability, suggesting that rhythm skills and rapid processing skills may need particular attention in musical training with dyslexics (Overy et al., 2003). Although classroom music lessons had a positive effect on phonologic and spelling skills alongside with rhythm copying and rapid auditory processing skills in dyslectic children, they did not influence reading skills (Overy, 2003).

Many of these studies are based on a few individuals under specific test situations, and it may be difficult to rule out socioeconomical and cultural factors. To investigate if there are preexisting neural, cognitive, or motor markers for musical abilities, 5- to 7-year-olds beginning piano or string lessons were compared with children of the same age not beginning musical training (Norton et al., 2005). All the children received a series of visual-spatial, nonverbal reasoning, verbal, motor and musical tests, and fMRI. No neural, cognitive, motor, or musical differences were found between the groups, and there was no correlation between musical perceptual skills and any brain or visual-spatial measures. However, correlations were found between musical perceptual skills and nonverbal reasoning and phonemic awareness, which could be due either to innate abilities or implicit learning during early development or both (Norton et al., 2005). This report is a baseline study of an ongo- 
ing longitudinal study addressing the effect of intensive musical training on brain and cognitive development.

Considering the different roles of prosody, rhythm, stress, and tone in individual languages and music systems, transcultural and translinguistic studies on the effect of music on reading skills would be interesting. Most children like to listen to music, and experimental data indicate that a stimulating environment has many biochemical and molecular effects on the brain, and can increase the number of neuronal connections. To learn to play an instrument involves motor, auditory, and cognitive skills such as memorizing long melody sequences and translating musical symbols into motor sequences during sightreading, a most challenging musical skill with extreme demands on real-time information processing. It is, therefore, not unreasonable to assume that music can be of benefit for dyslexic children, but more studies are needed to verify a significant effect. A question that should be addressed is to what extent a possible positive effect of music on reading is specific or if a similar effect could be achieved by other activities of similar complexity.

\section{CONCLUDING REMARKS}

Language training needs priority in education. Specific problems in subgroups of dyslexic children need to be identified (Shu et al., 2005). Knowledge in more than the native language has long been a necessity in many parts of the world, and is of increasing importance today. As reviewed by Perani and Abutalebi (2005), most available data indicate that the first and second languages are processed by the same networks, and that differences in first and second languages representations are mainly related to the specific demands, which vary according to the age of acquisition, the degree of mastery, and the level of exposure to each language. The acquisition of a second language could be considered as a dynamic process, requiring additional neural resources in specific circumstances.

The neuroscience of language is a rapidly progressing area of research, but we are still at an early stage of understanding to what extent linguistic and cultural factors influence the brain organization of language. All methods used referred to in this review have their limitations and combinations of different techniques should be utilized whenever possible.

Some basic knowledge on how the brain works may help in evaluating imaging studies. The brain represents about $2 \%$ of 
the body weight but accounts for about $20 \%$ of the oxygen and calories consume by the body. The high metabolic activity is present independent of whether we are resting or doing something. During specific activations, a redistribution of the cerebral blood flow takes place, which is comparatively small compared to the basal metabolic requirement that is considered to be about $85 \%$ and has to be deducted in studies using fMRI and PET in order to detect the changes (see Gusnard \& Raichle, 2001; Hyder, Rothman, \& Shulman, 2002; Raichle \& Gusnard, 2002; Shulman, Rothman, Behar, \& Hyder, 2004). What is counted as background will influence the results.

Another factor to consider is that neural activation is modulated by task demands, and that increasing skill and automatic processing can reduce the neural activation (Pascual-Leone et al., 2005; Petersen, van Mier, Fiez, \& Raichle, 1998). Thus, high activation does not necessarily mean better function, a fact that makes longitudinal studies in which skill and activation can be followed important. Furthermore, the high spatial resolution obtained with fMRI still represents millions of neurons, and one neuron can have contact with thousands of other neurons and take part in many different networks. The evidence for overlapping in language and music processing observed in functional imaging (Koelsch et al., 2004; Maess, Koelsch, Gunder, \& Friederici, 2001) thus cannot tell us whether it is the same neuronal population, or if there are functionally independent neuronal populations, in close spatial proximity. For further discussion, see the review by Price, Thierry, and Griffiths (2005).

Although this review mainly deals with the cortical representation of language and reading, it is evident that some processing takes place at lower levels, maybe even in the primary auditory input to the brain via the brain stem (Krishnan, Xu, Gandour, \& Cariani, 2005; Wibble, Nichol, \& Kraus, 2004), and that cortical language processing interacts with the basal ganglia, other subcortical regions and cerebellum in various linguistic components (Ito, 2005; Jansen et al., 2005; Klein, Watkins, Zatorre, \& Milner, 2006; Vargha-Khadem, Gadian, Copp, \& Mishkin, 2005; Xiang et al., 2003).

\section{ACKNOWLEDGEMENTS}

I thank Professor Ingvar Lundberg, Department of Psychology, Göteborg University, Sweden, and the editor of Annals of Dyslexia, Professor Che Kan Leong, for interesting discussions and valuable comments on the manuscript. 


\section{Address correspondence to: Barbro B. Johansson, M.D., Wallenberg Neuroscience Center, Experimental Brain Research, BMC A13, SE 22184 Lund, Sweden. E-mail: Barbro.Johansson @med.lu.se; phone +46-46-222-0621; fax +46-46-222-0626}

\section{References}

Abrams, R. M., \& Gerhardt, K. J. (2000). The acoustic and environment and physiological responses of the fetus. Journal of Perinatology, 20, S30-S35.

Abu-Rabia, S., \& Siegel, L. S. (2002). Reading, syntactic, orthographic, and working memory skills of bilingual Arabic-English-speaking Canadian Children. Journal of Psycholinguistic Research, 31, 661-678.

Amedi, A., Floel, A., Knecht, S., Zohary, E., \& Cohen, L. G. (2004). Transcranial magnetic stimulation of the occipital pole interferes with verbal processing in blind subjects. Nature Neuroscience, 7, 1266-1270.

Anvari, S. H., Trainor, L. J., Woodside, J., \& Levy, B. A. (2002). Relations among musical skills, phonological processing, and early reading ability in preschool children. Journal of Experimental Child Psychology, 83, 111-130.

Baddeley, A. (2003). Working memory: Looking back and looking forward. Nature Reviews Neuroscience, 4, 829-839.

Baddeley, A., Gathercole, S., \& Papagno, C. (1998). The phonological loop as a language learning device. Psychological Review, 105, 158-173.

Balsamo, L. M., Xu, B., Grandin, C. B., Petrella, J. R., Braniecki, S. H., Elliott, T. K., \& Gaillard, W. D. (2002). A functional magnetic resonance imaging study of left hemisphere language dominance in children. Archives of Neurology, 59, 1168-1174.

Bavelier, D., Brozinsky, C., Tomann, A., Michell. T., Neville, H., \& Liu, G. (2001). Impact of early deafness and early exposure to sign language on the cerebral organization for motion processing. Journal of Neuroscience, 21, 8931-8942.

Bavelier, D., \& Neville, H. (2002). Cross-modal plasticity: Where and how? Nature Reviews Neuroscience, 3, 443-452.

Bertoncini, J., Morais, J., Bijeljac-Babic, R., McAdams, S., Peretz, I., \& Mehler, J. (1989). Dichotic perception and laterality in neonates. Brain and Language, 37, 591-605.

Best, C. T., Hoffman, H., \& Glanville, B. B. (1992). Development of infant ear asymmetries in speech and music. Perception in Psychophysics, 31, 75-85.

Bolger, D. J., Perfetti, C. A., \& Schneider, W. (2005). Cross-cultural effect on the brain revisited: Universal structures plus writing system variation. Human Brain Mapping, 25, 93-104.

Brambati, S. M., Termine, C., Ruffino, M., Stella, G., Fazio, F., Cappa, S. F., \& Perani, D. (2004). Regional reductions of gray matter volume in familial dyslexia. Neurology, $63,742-745$.

Browman, C. P., \& Goldstein, L. (1992). Articulatory phonology: An overview. Phonetica, 49, 155-180.

Buonomano, D. V., \& Merzenich, M. M. (1998). Cortical plasticity: From synapses to maps. Annual Review of Neuroscience, 21, 149-186.

Calvert, G. A., Campbell, R., \& Brammer, M. J. (2000). Evidence from functional magnetic imaging of crossmodel binding in the human heteromodal cortex. Current Biology, 10, 649-657. 
Castro-Caldas, A., Cavaleiro Miranda P., Carmo, I., Reis, A., Laote, F., Ribeiro, D., \& Ducla-Soares, E. (1999). Influence of learning to read and write on the morphology of the corpus callous. European Journal of Neurology, 67, 23-28.

Castro-Caldas, A., Petersson, K. M., Reis, A., Stone-Elander, S., \& Ingvar, M. (1998). The illiterate brain. Learning to read and write during childhood influences the functional organization of the adult brain. Brain, 121, 1053-1063.

Chee, M. W., Caplan, D., Soon, C. S., Sriram, N., Tan, E. W., Thiel, T., \& Weeks, B. (1999). Processing of visually presented sentences in Mandarin and English studied with fMRI. Neuron, 33, 127-137.

Chee, M. W. L., Soon, C. S., Lee, H. L., \& Pallier, C. (2004). Left insula activation: A marker for language attainment in bilinguals. Proceedings of the National Academy of Sciences of the United States of America, 101, 15265-15270.

Chee, M. W., Tan, E. W. L., \& Thiel, T. (1999). Mandarin and English single word processing studies with functional magnetic resonance imaging. Journal of Neuroscience, 19, 3050-3056.

Cheung, H. (1996). Nonword span as a unique predictor of second-language vocabulary learning. Developmental Psychology, 32, 867-873.

Cho, J.-R., \& Chen, H.-C. (2005). Somantic and phonological processing in reading Korean Hangul and Hanja words. Journal of Psycholinguistic Research, 34, 401-414.

Cohen, L., Lehericy, S., Chochon, F., Lemer, C., Rivaud, S., \& Dehaene, S. (2002). Language-specific tuning of visual cortex? Functional properties of the visual word form area. Brain, 125, 1054-1069.

Cohen, L., Lehericy, S., Henry, C., Bourgeois, M., Larroque, C., Sainte-Rose, C., Dehaene, S., \& Hertz-Pannier, L. (2004). Learning to read without a left occipital lobe: Righthemispheric shift of visual word form area. Annals of Neurology, 56, 890-894.

Corballis, M. C. (2002). From hand to mouth. The origins of language. Princeton, NJ: Princeton University Press.

Corballis, M. C. (2003). From mouth to hand: Gesture, speech, and the evolution of righthandedness. Behavioral Brain Science, 26, 199-208.

Courtney, S. M., Petit, L., Maisog, J. M., Ungerleider, L. G., \& Haxby, J. V. (1998). An area specialized for spatial working memory in human frontal cortex. Science, $279,1347-1351$.

De Groot, A. M. B., Borgwaldt, S., Bos, M., \& van den Eijnden, E. (2002). Lexical decision and word naming in bilinguals: Language effects and task effects. Journal of Memory and Language, 47, 91-124.

Dehaene, S., Cohen, L., Sigman, M., \& Vinckier, F. (2005). The neural code for written words: A proposal. Trends in Cognitive Sciences, 9, 335-341.

Eden, G. F., Jones, K. M., Cappelli, K., Gareau, L., Wood, F. B., Zeffiro, T. A., Dietz, N. A. E., Agnew, J. A., \& Flowers, D. L. (2004). Neural changes following remediation in adult developmental dyslexia. Neuron, 44, 411-422.

Engel, A. K., Moll, C. K., Fried, I., \& Ojemann, G. A. (2005). Invasive recordings from the human brain: Clinical insights and beyond. Nature Reviews Neuroscience, 6, 35-47.

Fadiga, L., Craighero, L., Buccino, G., \& Rizzolatti, G. (2002). Speech listening specifically modulated the tongue muscles: A TMS study. European Journal of Neuroscience, 15, 399-402.

Floel, A., Ellger, T., Breitenstein, C., \& Knecht, S. (2003). Language perception activates the hand motor cortex: Implications for motor theories of speech perception. European Journal of Neuroscience, 18, 704-708.

Friederici, A. D., \& Alter, K. (2004). Lateralization of auditory language function: A dynamic dual pathway model. Brain and Language, 89, 267-276.

Friedrich, C. K., Kotz, S. A., Friederici, A. D., \& Alter, K. (2004). Pitch modulates lexical identification in spoken word recognition: ERP and behavioral evidence. Brain Research Cognitive Brain Research, 20, 300-308. 
Frost, S. B., Barbay, S., Friel, K. M., Plautz, E. J., \& Nudo, R. J. (2003). Reorganization of remote cortical regions after ischemic brain injury: A potantial substrate for stroke recovery. Journal of Neurophysiology, 89, 3205-3214.

Geschwind, N. (1965). Disconnecting syndrome in animal and man. Brain, 88, 237-294, $585-644$.

Geva, E. (2000). Issues in the assessment of reading disabilities in L2 children-beliefs and research evidence. Dyslexia, 6, 13-28.

Gougoux, F., Lepore, F., Lassonde, M., Voss, P., Zatorre, R. J., \& Belin, P. (2004). Pitch discrimination in the early blind. Nature, 420, 309.

Gusnard, D. A., \& Raichle, M. E. (2001). Searching for a baseline: Functional imaging and the resting human brain. Nature Reviews Neuroscience, 2, 685-694.

Hairston, W. D., Burdette, J. H., Flowers, D. L., Wood, F. B., \& Wallace, M. T. (2005). Altered temporal profile of visual-auditory multisensory interactions in dyslexia. Experimental Brain Research, 166, 474-480.

Hanavan, K., \& Coney, J. (2005). Hemispheric asymmetry in the processing of Japanese script. Laterality, 10, 413-428.

Helland, T., \& Kaasa, R. (2005). Dyslexia in English as a second language. Dyslexia, 11, $41-60$.

Hickmott, P. W., \& Merzenich, M. M. (2002). Local circuit properties underlying cortical reorganization. Journal of Neurophysiology, 88, 1288-1301.

Hickok, G., Buchsbaum, B., Humphries, C., \& Muftuler, T. (2003). Auditory-motor interaction revealed by fMRI: Speech, music, and working memory in area Spt. Journal of Cognitive Neuroscience, 15, 673-682.

Hickok, G., \& Poeppel, D. (2004) Dorsal and ventral streams: A framework for understanding aspects of the functional anatomy of language. Cognition, 92, 62-99.

Ho, C. S.-H., \& Fong, K.-M. (2005). Do Chinese dyslexic children have difficulties learning English as a second language? Journal of Psycholinguistic Research, 34, 603-618.

Ho, Y. C., Cheung, M. C., \& Chan, A. C. (2003). Music training improves verbal but not visual memory: Cross-sectional and longitudinal explorations in children. Neuropscyhology, 17, 439-450.

Horwitz, B., Rumsey, J. M., \& Donohue, B. C. (1998). Functional connectivity of the angular gyrus in normal reading and dyslexia. Proceedings of the National Academy of Sciences of the United States of America, 95, 8939-8944.

Hyder, F., Rothman, D. L., \& Shulman, R. G. (2002). Total neuroenergetics support localized brain activity: Implications for the interpretation of fMRI. Proceedings of the National Academy of Sciences of the United States of America, 99, 10771-10776.

Illes, J., Francis, W. S., Desmond, J. E., Gabrieli, J. D., Glover, G. H., Poldrack, R., Lee, C. J., \& Wagner, A. D. (1999). Convergent cortical representation of semantic processing in bilinguals. Brain and Language, 70, 347-363.

Ingvar, M., af Trampe, P., Greitz, T., Eriksson, L., Stone-Elander, S., \& von Euler, C. (2002). Residual differences in language processing in compensated dyslexics revealed in simple word reading tasks. Brain and Language, 83, 249-267.

Ito, M. (2005). Bases and implications of learning in the cerebellum-adaptive control and internal model mechanism. Progress in Brain Research, 148, 95-109.

Jansen, A., Floel, A., Van Randenborgh, J., Konrad, C., Rotte, M., Forster, A. F., Deppe, M., \& Knecht, S. (2005). Crossed cerebro-cerebellar language dominance. Human Brain Mapping, 24, 165-172.

Johansson, B. B. (2000). Brain plasticity and stroke rehabilitation. The Willis lecture. Stroke, 31, 223-231.

Johansson, B. B. (2004a). Functional and cellular effects of environmental enrichment after experimental brain infarcts. Restorative Neurology and Neuroscience, 22, 163-174. 
Johansson, B. B. (2004b). Brain plasticity in health and disease. Keio Journal of Medicine, $53,231-246$.

Johansson, B. B. (2006). Music and brain plasticity. European Review, 14, $29-44$.

Jung-Beeman, M. (2005). Bilateral brain processes for comprehending natural language. Trends in Cognitive Sciences, 9, 512-518.

Kao, S. R., Leong, C. K., \& Gao, D.-G. (Eds.). (2002). Cognitive neuroscience studies of the Chinese language. Hong Kong: Hong Kong University Press.

Kilgour, A. R., Jakobson, L. S., \& Cuddy, L. L. (2000). Music training and rate of presentation as mediators of text and song recall. Memory $\mathcal{E}$ Cognition, 28, 700-710.

Kim, K. H., Relkin, N. R., Lee, K. M., \& Hirsch, J. (1997). Distinct cortical areas associated with native and second languages. Nature, 388, 171-174.

Klein, D., Watkins, K. E., Zatorre, R. J., \& Milner, B. (2006). Word and nonword repetition in bilingual subjects: A PET study. Human Brain Mapping, 27, 153-161.

Klingberg, T., Hedehus, M., Temple, E., Salz, T., Gabrieli, J. D., Moseley, M. E., \& Poldrack, R. A. (2000). Microstructure of temporo-parietal white matter as a basis for reading ability: Evidence from diffusion tensor magnetic resonance imaging. Neuron, 25, 493-500.

Knecht, S., Floel, A., Breitenstein, C., Sommer, J., Henningsen, H., Ringelstein, E. B., \& Pascual-Leone, A. (2002). Degree of language lateralization determines language susceptibility to unilateral brain lesions. Nature Neuroscience, 5, 695-699.

Kochunov, P., Fox, P., Lancaster, J., Tan, L. H., Amunts, K., Zilles, K., Mazziotta, J., \& Gao, J. H. (2003). Localized morphological brain differences between Englishspeaking Caucasians and Chinese-speaking Asians: New evidence of anatomical plasticity. Neuroreport, 14, 961-964.

Koelsch, S., Kasper, E., Sammler, D., Schulze, K., Gunter, T., \& Friederici, A. D. (2004). Music, language and meaning: Brain signatures of semantic processing. Nature Neuroscience, 7, 302-307.

Krishnan, A., Xu, Y., Gandour, J., \& Cariani, P. (2005). Encoding pitch in the human brainstem is sensitive to language experience. Cognitive Brain Research, 25, $161-168$.

Kuhl, P. K. (2004). Early language acquisition: Cracking the speech code. Nature Reviews Neuroscience, 5, 831-843.

Kuhl, P. K., Andrusko, J. E., Chistovich, I. A., Chistovich, L. A., Kozhevnikova, E. V., Ryskina, N. L., Stolyarova, E. L., Sundberg, U., \& Lacerda, F. (1997). Crosslanguage analysis of phonetic units in language addressed to infants. Science, 277, 684-686.

Kunesch, E., Classen, J., Bettag, M., Kahn, T., Ulrich, F., Bock, W. J., Freund, H. J., \& Seitz, R. J. (2003). Representational cortical plasticity associated with brain tumours: Evidence from laser-induced interstitial thermotherapy. Acta Neurologica Scandinavica, 108, 201-208.

Laasonen, M., Lahti-Nuuttila, P., \& Virsu, V. (2001). Temporal order and processing acuity of visual, auditory, and tactile perception in developmentally dyslexic young adults. Cognitive, Affective, \& Behavioral Neuroscience, 1, 394-410.

Laasonen, M., Service, E., \& Virsu, V. (2002). Crossmodal temporal order and processing acuity in developmentally dyslexic young adults. Brain and Language, 80, 340-354.

Laasonen, M., Tomma-Halme, J., Lahti-Nuuttila, P., Service, E., \& Virsu, V. (2000). Rate of information segregation in developmentally dyslexic children. Brain and Language, 75, 66-81.

Leong, C. K. (1997). Paradigmatic analysis of Chinese word reading: Research findings and classroom practices. In C. K. Leong \& R. M. Joshi (Eds.), Cross-language stud- 
ies of learning to read and spell: Phonologic and orthographic processing (pp. 379-417). Dordrecht: Kluwer Academic Publishers.

Leong, C. K. (2002). Cognitive conjunction analysis of processing Chinese. In H. S. R. Kao, C. K. Leong, \& D.-G. Gao (Eds.), Cognitive neuroscience studies of the Chinese language (pp. 1-31). Hong Kong: Hong Kong University Press.

Lessard, N., Pare, M., Lepore, F., \& Lassonde, M. (1998). Early-blind human subjects localize sound sources better than sighted subjects. Nature, 395, 278-280.

Li, P., Jin, Z., \& Tan, L. H. (2004). Neural representations of nouns and verbs in Chinese: An fMRI study. NeuroImage, 21, 1533-1541.

Liberman, A. M., \& Mattingly, I. G. (1985). The motor theory of speech perception revised. Cognition, 21, 1-36.

Liberman, A. M., \& Whalen, D. H. (2000). On the relation of speech to language. Trends in Cognitive Sciences, 4, 187-196.

Lucas, T. H., McKhann, G. M., \& Ojemann, G. A. (2004). Functional separation of languages in the bilingual brain: A comparison of electrical stimulation language mapping in 25 bilingual patients and 117 monolingual control patients. Journal of Neurosurgery, 101, 449-457.

Lundberg, I. (2002). Second language learning and reading with the additional load of dyslexia. Annals of Dyslexia, 52, 165-187.

Maess, B., Koelsch, S., Gunter, T., \& Friederici, A. D. (2001). Musical syntax is processed in Broca's area: an MEG study. Nature Neuroscience, 4, 540-545.

McBride-Chang, C., Bialystok, E., Chong, K. K. Y., \& Li, Y. (2004). Levels of phonological awareness in three cultures. Journal of Experimental Child Psychology, 89, 93-111.

McCrory, E. J., Mechelli, A., Frith, U., \& Price, C. J. (2005). More than words: A common neural basis for reading and naming deficits in developmental dyslexia? Brain, $128,261-267$.

McGurk, H., \& MacDonald, J. (1976). Hearing lips and seeing voices. Nature, 265, 746-748.

Mechelli, A., Crinion, J. T., Noppeney, U., O’Doherty. J., Ashburner, J., Frackowiak, R. S., \& Price, C. J. (2004). Structural plasticity in the bilingual brain. Nature, 431, 757.

Meister, I. G., Boroojerdi, B., Foltys, H., Sparing, R., Huber, W., \& Topper, R. (2003). Motor cortex hand area and speech: Implications for the development of language. Neuropsychologia, 41, 401-406.

Meyer, M., Alter, K., Friederici, A. D., Lohmann, G., \& von Cramon, D. Y. (2002). FMRI reveals brain regions mediating slow prosodic modulations in spoken sentences. Human Brain Mapping, 17, 73-88.

Miller-Guron, L., \& Lundberg, I. (2000). Dyslexia and second language reading: A second bite at the apple. Reading and Writing: An Interdisciplinary Journal, 12, $41-61$.

Miller-Guron, L., \& Lundberg, I. (2003). Identifying dyslexia in multilingual students: Can phonological awareness be assessed in the majority language? Journal of Research in Reading, 26, 69-82.

Miyazaki, S., Kojio, E., Sinohara, Y., Ogata, A., Hisada, N., \& Narita, S. ( 1995). Categorization of primary school children with learning difficulty and a study on remediation methods. Japanese National Research Institute of Special Education, Report C, 28, 7-36.

Nakamura, K., Dehaene, S., Jobert, A., Le Bihan, D., \& Kouider, S. (2005). Subliminal convergence of Kanji and Kana words: Further evidence for functional parcellation of the posterior temporal cortex in visual word perception. Journal of Cognitive Neuroscience, 17, 954-968. 
Navarra, J., \& Soto-Faraco, S. (2005, December). Hearing lips in a second language: Visual articulatory information enables the perception of second language sounds. Psychological Research, 1-9 [Epub ahead of print].

Nazzi, T., Bertoncini, J., \& Mehler, J. (1998). Language discrimination by newborns: Toward an understanding in the role of rhythm. Journal of Experimental Human Perception Performance, 24, 756-766.

Neville, H., \& Bavelier, D. (2002). Human brain plasticity: Evidence from sensory deprivation and altered language experience. Progress in Brain Research, 138, 177-188.

Nishitani, N., Schürmann, M., Amunts, K., \& Hari, R. (2005). Broca's region: From action to language. Physiology, 20, 60-69.

Norton, A., Winner, E., Cronin, K., Overy, K., Lee, D. J., \& Schlaug, G. (2005). Are there preexisting neural, cognitive, or motoric markers for musical ability? Brain and Cognition, 59, 124-134.

Oh, J. S., Knightly, L. M., \& Au, T. K. (2003). Holding on to childhood language memory. Cognition, 86, B53-B64.

Ojemann, S. G., Berger, M. S., Lettich E., \& Ojemann, G. A. (2003). Localization of language function in children: Results of electrical stimulation mapping. Journal of Neurosurgery, 98, 465-470.

Ojemann, G. A., \& Whitaker, H. A. (1978). The bilingual brain. Archives of Neurology, 35, 409-412.

Orton, S. T. (1937). Reading, writing and speech problems in children. New York: Norton.

Overy, K. (2003). Dyslexia and music. From timing decifits to musical intervention. Annals of the New York Academy of Sciences, 999, 497-505.

Overy, K., Nicolson, R. I., Fawcett, A. J., \& Clarke, E. F. (2003). Dyslexia and music: Measuring musical timing skills. Dyslexia, 9, 18-36.

Pallier, C., Dehaene, S., Boline, J. B., LeBihan, D., Argenti, A.-M., Dupoux, E., \& Mehler, J. (2003). Brain imaging of language plasticity in adopted adults: Can a second language replace the first? Cerebral Cortex, 13, 155-161.

Paradis, M. (1995). Aspects of bilingual aphasia. Oxford: Pergamon.

Pascual-Leone, A., Amedi, A., Fregni, F., \& Merabet, L. B. (2005). The plastic human brain cortex. Annual Review of Neuroscience, 28, 377-401.

Pataraia, E., Simos, P. G., Castillo, E. M., Billingsley-Marshall, R. L., McGregor, A. L., Breier, J. I., Sarkari, S., \& Papanicolaou, A. C. (2004). Reorganization of language-specific cortex in patients with lesions or mesial temporal epilepsy. Neurology, 23, 1825-1832.

Paulesu, E., Demonet, J. F., Fazio, F., McCrory, E., Chanoine, V., Brunswick, N., Cappa, S. F., Cossu, G., Habib, M., Frith, C. D., \& Frith, U. (2001). Dyslexia: Cultural diversity and biological unity. Science, 291, 2165-2167.

Paulesu, E., Frith, U., Snowling, M., Gallagher, A., Morton, J., Richard, S. J., Frackowiak, R. S., \& Frith, C. D. (1996). Is developmental dyslexia a disconnection syndrome? Evidence from PET scanning. Brain, 119, 143-157.

Pena, M., Maki, A., Kovacic, D., Dahaene-Lambertz, C., Koizumi, H., Bouquet, F., \& Mehler, J. (2003). Sound and silence: An optical topography study of language recognition at birth. Proceedings of the National Academy of Sciences of the United States of America, 100, 11702-11705.

Perani, D., \& Abutalebi, J. (2005). The neural basis of first and second language processing. Current Opinions in Neurobiology, 15, 202-206.

Perani, D., Abutalebi, J., Paulesu, E., Brambati, S., Scifo, P., Cappa, S. F., \& Fazio, F. (2003). The role of age of acquisition and language usage in early, high-proficient bilinguals: A fMRI study during verbal fluency. Human Brain Mapping, 19, 170-182.

Perani, D., Paulesu, E., Galles, N. S., Dupoux, E., Dehaene, S., Bettinardi, V., Cappa, S. F., Fazio, F., \& Mehler, J. (1998). The bilingual brain. Proficiency and age of acquisition of the second language. Brain, 121, 1841-1852. 
Perfetti, C. A. (2003). The universal grammar of reading. Scientific Studies of Reading, 7, $3-24$.

Perfetti, C. A., Liu, Y., \& Tan, L.-H. (2002). How the mind can meet the brain in reading: A comparative writing systems approach. In H. S. R. Kao, C. K. Leong, \& D.-G. Gao (Eds.), Cognitive neuroscience studies of the Chinese language (pp. 35-59). Hong Kong: Hong Kong University Press.

Petersen, S., van Mier, H., Fiez, J. A., \& Raichle, M. (1998). The effect of practice on the functional anatomy of performance. Proceedings of the National Academy of Sciences of the United States of America, 95, 853-860.

Petersson, K. M., Reis, A., Askelof, S., Castro-Caldas, A., \& Ingvar, M. (2000). Language processing modulated by literacy: A network analysis of verbal repetition in literate and illiterate subjects. Journal of Cognitive Neuroscience, 12, 364-382.

Petitto, L. A., \& Marentette, P. F. (1991). Babbling in the manual mode: Evidence for the ontogeny of language. Science, 251, $1493-1496$.

Poeppel, D. (2001). Pure word deafness and the bilateral processing of the speech code. Cognitive Science, 25, 679-693.

Poeppel, D. (2003). The analysis of speech in different temporal windows: Cerebral lateralization as asymmetric sampling in time. Speech Communication, 41, 245-255.

Poeppel, D., \& Hickok, G. (2004). Towards a new functional anatomy of language. Cognition, 92, 1-12.

Price, C. J. (2000). The anatomy of language: Contributions from functional imaging. Journal of Anatomy, 197, 335-359.

Price, C. J., \& Mechelli, A. (2005). Reading and reading disturbance. Current Opinions in Neurobiology, 15, 231-238.

Price, C., Thierry, G., \& Griffiths, T. (2005). Speech-specific auditory processing: Where is it? Trends in Cognitive Sciences, 9, 271-276.

Pujol, J., Deus, J., Losilla, J. M., \& Capdevila, A. (1999). Cerebral lateralization of language in normal left-handed people studied by functional MRI. Neurology, 52, 1038-1043.

Raichle, M. E., \& Gusnard, D. A. (2002). Appraising the brain¥s energy budget. Proceedings of the National Academy of Sciences of the United States of America, 99, 10237-10239.

Rizzolatti, G., \& Arbib, M. A. (1998). Language within our grasp. Trends in Neuroscience, 21, 188-194.

Rizzolatti, G., \& Craighero, L. (2004). The mirror-neuron system. Annual Review of Neurosciences, 27, 169-192.

Roder, B., Stock, O., Bien, S., Neville, H., \& Rosler, F. (2002). Speech processing activates visual cortex in congenitally blind humans. European Journal of Neuroscience, 16, 930-936.

Roder, B., Teder-Salejarvi, W., Sterr, A., Rosler, F., Hillyard, S. A., \& Neville, H. J. (1999). Improved auditory spatial tuning in blind humans. Nature, 400, 162-166.

Rorden, C., \& Karnath, H.-O. (2004). Using human brain lesions to infer function: A relic from a past era in the fMRI age? Nature Reviews Neuroscience, 5, 813-819.

Roux, F. E., Lubrano, V., Lauwers-Cances, V., Tremoulet, M., Mascott, C. R., \& Demonet, J. F. (2004). Intra-operative mapping of cortical areas involved in reading in mono- and bilingual patients. Brain, 127, 1796-1810.

Rumsey, J. M., Horwitz, B., Donohue, B. C., Nace, K. L., Maisog, J. M., \& Andreason, P. (1999). A functional lesion in developmental dyslexia: Left angular gyral blood flow predicts severity. Brain and Language, 70, 187-204.

Saffran, J. R. (2001). Words in a sea of sounds: The output of infant statistical learning. Cognition, 81, 149-169.

Saffran, J. R. (2003). Statistical language learning: Mechanisms and constraints. Current Directions in Psychological Science, 12, 110-114. 
Saffran, J. R., Aslin, R. N., \& Newport, E. L. (1996). Statistical learning by 8-month-old infants. Science, 274, 1926-1928.

Saffran, J. R., \& Wilson, D. (2003). From syllables to syntax: Multi-level statistical learning by 12-month-old infants. Infancy, 4, 273-284.

Sandler, W., Meir, I., Padden, C., \& Aronoff, M. (2005). The emergence of grammar: Systematic structure in a new language. Proceedings of the National Academy of Sciences of the United States of America, 102, 2661-2665.

Schon, D., Magne, C., \& Besson, M. (2004). The music of speech: Music training facilitates pitch processing in both music and language. Psychophysiology, 41, 341-349.

Seitz, R. J., Butefisch, C. M., Kleiser, R., \& Homberg, V. (2004). Reorganization of cerebral circuits in human ischemic disease. Restorative Neurology and Neuroscience, 22, 207-229.

Seitz, R. J., Huang, Y., Knorr, U., Tellmann, L., Herzog, H. \& Freund, H. J. (1995). Largescale plasticity of the human motor cortex. Neuroreport, 6, 742-744.

Seki, A., Okada, T., Koeda, T., \& Sadato. N. (2004). Phonemic manipulation in Japanese: An fMRI study. Cognitive Brain Research, 20, 261-272.

Senghas, A. (2005). Language emergence. Clues from a new Bedouin sign language. Current Biology, 15, R463-R465.

Senghas, A., Kita, S., \& Özyürek, A. (2004). Children creating core properties of language: Evidence from an emerging in sign language in Nicaragua. Science, 305, $1779-1782$.

Service, E. (1992). Phonology, working memory, and foreign-language learning. Quarterly Journal of Experimental Psychology, 45A, 21-50.

Shapiro, K. A., Mottaghy, F. M., Schiller, N. O., Poeppel, T. D., Flüss, M. O., Müller, H.-W., Caramazza, A., \& Krause, B. I. (2005). Dissociating neural correlates for nouns and verbs. NeuroImage, 24, 1058-1067.

Shaywitz, B. A., Shaywitz, S. E., Blachman, B. A., Pugh, K. R., Fulbright, R. K., Skudlarski, P., Mencl, W. E., Constable, R. T., Holahan, J. M., Marchione, K. E., Fletcher, J. M., Lyon, G. R., \& Gore, J. C. (2004). Development of left occipitotemporal systems for skilled reading in children after a phonologically based intervention. Biological Psychiatry, 55, 926-933.

Shaywitz, S. E., \& Shaywitz, B. A. (2005). Dyslexia (specific reading disability). Biological Psychiatry, 57, 1301-1309.

Shu, H., Meng, X., Chen, X., Luan, H., \& Cao, F. (2005). The subtypes of developmental dyslexia in Chinese: Evidence from three cases. Dyslexia, 11, 311-329.

Shulman, R. G., Rothman, D. L., Behar, K. L., \& Hyder, F. (2004). Energetic basis of brain activity: Implications for neuroimaging. Trends in Neurosciences, 8, 489-495.

Silani, G., Frith, U., Demonet, J.-F., Fazio, F., Perani, D., Price, D., Frith, C. D., \& Paulesu, E. (2005). Brain abnormalities underlying altered activation in dyslexia: A voxel based morphometry study. Brain, 128, 2453-2461.

Simos, P. G., Breier, J. I., Fletcher, J. M., Foorman, B. R., Mouzaki, A., \& Papanicolaou, A. C. (2001). Age-related changes in regional brain activation during phonological decoding and printed word recognition. Developmental Neuropsychology, 19, 191-210.

Siok, W. T., Perfetti, C. A., Jin, Z., \& Tan, L. H. (2004). Biological abnormality of impaired reading is constrained by culture. Nature, 431,71-76.

Tan, L. H., Liu, H. L., Perfetti, C. A., Spinks, J. A., Fox, P. T., \& Gao, J. H. (2001). The neural system underlying Chinese logograph reading. Neuroimage, 13, 836-846.

Tan, L. H., Spinks, J. A., Eden, G. F., Perfetti, C. A., \& Siok, W. T. (2005). Reading depends on writing, in Chinese. Proceedings of the National Academy of Sciences of the United States of America, 102, 8781-8785. 
Tan, L. H., Spinks, J. A., Feng, C. M., Siok, W. T., Perfetti, C. A., Xiong, J., Fox, P. T., \& Gao, J. H. (2003). Neural systems of second language reading are shaped by native language. Human Brain Mapping, 18, 158-166.

Tan, L. H., Spinks, J. A., Gao, J. H., Liu, A., Perfetti, C. A., Xiong, J., Pu, Y., Liu, Y., Stofer, K. A., \& Fox, P. T. (2000). Brain activation in the processing of Chinese characters and words: A functional MRI study. Human Brain Mapping, 10, 16-27.

Tees, R. C., \& Werker, J. (1984). Perceptual flexibility: Maintenance or recovery of the ability to discriminate non-native speech sounds. Canadian Journal of Psychology, $38,579-590$.

Temple, E., Deutsch, G. K., Poldrack, R. A., Miller, S. L., Tallal, P., Merzenich, M. M., \& Gabrieli, J. D. (2003). Neural deficits in children with dyslexia ameliorated by behavioral remediation: Evidence from functional MRI. Proceedings of the National Academy of Sciences of the United States of America, 100, 2860-2865.

Thiessen, E. D., \& Saffran, J. R. (2003). When cues collide: Use of stress and statistical cues to word boundaries by 7- to 9-month-old infants. Developmental Psychology, 39, 706-716.

Thompson, W. F., Schellenberg, E. G., \& Hussain, G. (2003). Perceiving prosody in speech. Effects of music lessons. Annals of the New York Academy of Sciences, 999, 530-532.

Thompson, W. F., Schellenberg, E. G., \& Hussain, G. (2004). Decoding speech prosody: Do music lesions help? Emotion, 4, 46-64.

Turkeltaub, P. E., Gareau, L., Flowers, D. L., Zeffiro, T. A., \& Eden, G. F. (2003). Development of neural mechanisms for reading. Nature Neuroscience, 6, 767-773.

Valaki, C. E., Maestu, F., Simos, P. G, Zhang, W., Fernandez, A., Amo, C. M., Ortiz, T. M., \& Papanicolaou, A. C. (2004). Cortical organization for receptive language functions in Chinese, English, and Spanish: A cross-linguistic MEG study. Neuropsychologia, 42, 967-979.

Van Wassenhove, V., Grant, K. W., \& Poeppel, D. (2005). Visual speech speeds up the neural processing of auditory speech. Proceedings of the National Academy of Sciences of the United States of America, 102, 1181-1186.

Vargha-Khadem, F., Gadian, D. G., Copp, A., \& Mishkin, M. (2005). FOXP2 and the neuroanatomy of speech and language. Nature Reviews Neuroscience, 6, 131-138.

Vouloumanus, A., \& Werker, J. F. (2004). Tuned to the signal: The privileged stuatus of speech for young infants. Developmental Science, 7, 270-276.

Wartenburger, I., Heekeren, H. R., Abutalebi, J., Cappa, S. F., Villringer, A., \& Perani, D. (2003). Early setting of grammatical processing in the bilingual brain. Neuron, 37, 159-170.

Wallace, M. T., Ramachandran, R., \& Stein, B. E. (2004). A revised view on sensory cortical parcellation. Proceedings of the National Academy of Sciences of the United States of America, 101, 2167-2172.

Wang, M., Perfetti, C. A., \& Liu, Y. (2005). Chinese-English biliteracy acquisition: Crosslangauge and writing system transfer. Cognition, 97, 67-88.

Ward, N. S., Brown, M. M., Thompson, A. J., \& Frackowiak, R. S. (2003). Neural correlates of motor recovery after stroke: A longitudinal fMRI study. Brain, 126, 2476-2496.

Weber, C., Hahne, A., Friederich, A., \& Frederici, A. D. (2004). Discrimination of word stress in early infant perception: Electrophysiological evidence. Cognitive Brain Research, 18, 149-161.

Weeks, R., Horwitz, B., Aziz-Sultan, A., Tian, B., Wessinger, C. M., Cohen, L. G., Hallett, M., \& Rauschecker, J. P. (2000). A positron emission tomographic study of auditory localization in the congenitally blind. Journal of Neuroscience, 20, 2664-2672. 
Werker , J., \& Lalonde, C. (1988). Cross-language speech perception: Initial capabilities and developmental change. Developmental Psychology, 24, 672-683.

Werker, J., \& Tees, R. C. (2005). Speech perception as a window for understanding plasticity and commitment in language systems of the brain. Developmental Psychobiology, 46, 233-251.

Wibble, B., Nicol, T., \& Kraus, N. (2004). Atypical brain stem representation of onset and formant structure of speech sounds in children with language-based learning problems. Biological Psychology, 67, 299-317.

Wolf, M., \& Goodglass, H. (1986). Dyslexia, dysnomia and lexical retrieval: A longitudinal investigation. Brain and Language, 28, 154-168.

Wydell, T. N. (1998). What matters in kanji word naming: Consistency, regularity, or On/Kun-reading difference? Reading and Writing: An Interdisciplinary Journal, 10, 359-373.

Wydell, T. N., \& Kondo, T. (2003). Phonological deficit and the reliance on orthographic approximation for reading: A follow-up study on an English-Japanese bilingual with monolingual dyslexia. Journal of Research in Reading, 26, 33-48.

Xiang, H., Lin, C., Ma, X., Zhang, Z., Bower, J., Weng, X., \& Gao, J. H. (2003). Involvement of the cerebellum in semantic discrimination: An fMRI study. Human Brain Mapping, 18, 208-214.

Xue, G., Dong, Q., Jin, Z., \& Chen, C. (2004). Mapping verbal working memory in nonfluent Chinese-English bilinguals with functional MRI. Neuroimage, 22, 1-10.

Zatorre, R. J., \& Belin, P. (2001). Spectral and temporal processing in human auditory cortex. Cerebral Cortex, 11, 946-953.

Zatorre, R. J., Belin, P., \& Penhune, V. B. (2002). Structure and function of auditory cortex: Music and speech. Trends in Cognitive Sciences, 6, 27-46.

Ziegler, J. C., Tan, J. H., Perry, C., \& Montant, M. (2000). The phonological frequency effect in written Chinese. Psychological Science, 11, 234-238.

Manuscript received January 15, 2006.

Final version accepted March 21, 2006. 